кандидат социологических наук, старший преподаватель кафедры государственного муниципального управления и социологии, заместитель декана по воспитательной работе факультета промышленной политики и бизнес-администрирования

Казанского национального исследовательского технологического университета

\section{ПРОБЛЕМЫ ПРОТИВОДЕЙСТВИЯ МОЛОДЕЖНОМУ КИБЕРЭКСТРЕМИЗМУ В УСЛОВИЯХ ИНТЕРНЕТ- СОЦИАЛИЗАЦИИ: ВОПРОС НРАВСТВЕННОГО ЗДОРОВЬЯ ПОДРАСТАЮЩЕГО ПОКОЛЕНИЯ}

Аннотация:

В статье представлены особенности и методы латентного рекрутинга молодежи в киберэкстремистскую деятельность в РФ, анализируются такие характеристики киберпреступности, как аморальность, анонимность, антисоциальность и др. Обосновывается необходимость выработки новых способов нравственной регуляции молодого поколения, соответствующих уровню современной информационной свободы. Проанализированы статистические данные о проявлениях виртуального экстремизма в социальных сетях на примере «ВКонтакте».

\section{Ключевые слова:}

информационный экстремизм, виртуальная мораль, сетевая социализация, виртуализация социальных институтов, социальные сети, интернет-пространство, информационно-коммуникационные технологии, молодежь, духовное здоровье, рекрутинг в экстремистские объединения, методы виртуального рекрутирования.
PhD in Social Science, Senior Lecturer, State, Municipal Administration and Social Science Department, Deputy Dean for Education Affairs, Industrial Policy and Business Administration School, Kazan National Research Technological University

\section{PROBLEMS OF COUNTERACTION TO YOUTH CYBER-EXTREMISM IN THE CONTEXT OF ONLINE SOCIALIZATION: CONCERNING MORAL HEALTH OF THE YOUNGER GENERATION}

Summary:

The article presents the features and the methods of latent recruiting of the youth in the cyber extremist activities in Russia, analyses such features of the cybercrime as immorality, anonymity, antisocial nature and others. The author substantiates the necessity to develop new ways of moral regulation of the younger generation corresponding to the modern information freedom. The paper analyses statistical data on the manifestations of virtual extremism in social networks by case study of VK social networking.

Keywords: information extremism, virtual morality, online socialization, virtualization of social institutions, social networks, Internet, ICT, youth, moral health, recruitment in extremist organizations, methods of virtual recruitment.

На сегодняшний день сформировался новый показатель статусной престижности - количество доступных первичных каналов информации [1, с. 177]. Теоретики информационного общества обозначили сети как новый тип институтов и выдвинули массу гипотез относительно последствий виртуализации классических социальных институтов. М. Кастельс заключал, что они, с одной стороны, способствуют развитию социальной организации, с другой - становятся механизмом «угнетения самобытности» [2, с. 232], что рано или поздно приводит общество к необходимости защищаться от глобализационных процессов. Преобразование социального пространства-времени в другую форму, симуляция структур, образов ряд исследователей представляют попыткой компенсировать отсутствие социальной реальности «киберпротезом» [3, с. 13]. Однако существует точка зрения, что социальные сети не способны «заменить старые и перерасти в новые институты» [4, с. 35]. К предпосылкам виртуализации как процесса симуляции институционального порядка следует относить не только научно-технологическое развитие, но и социальные факторы. Все чаще некоторые ученые обозначают социальные сети как ключевой компонент института «гражданской экспертизы» [5, с. 205], т. е. института оценивания социумом событий в области экономики, политики, достижений в культуре, науке и эффективности деятельности в данных сферах. Подобным образом формируется симулякр института общественного управления и экспертизы.

Информационный экстремизм вновь возвращает нас к вопросу формирования нового способа нравственной регуляции, так как виртуальная мораль тонкой гранью разделяет свободу и вседозволенность. В свете трагических декабрьских событий 2016 г. киберэкстремистскими были признаны некоторые комментарии молодых пользователей в социальных сетях, связанные с крушением Ту-154, убийством посла РФ в Турции А.Г. Карлова, после чего «ВКонтакте» запретила 
оставлять комментарии на страницах жертв. Большинство отечественных исследователей уже оценили деструктивную силу продуктов сетевого общества и пытаются определить приемлемые методы ликвидации данной интенции.

В качестве деструктивных социализирующих интенций социальных сетей выступают следующие:

1) образование новой формы отчуждения (сокращение доли реальных межличностных взаимодействий в пользу их аналога);

2) формирование нового способа нравственной регуляции (феномен «виртуальной морали» или, используя эвфемизм членов интернет-сообщества, «аморальной виртуали»);

3) фетишизация интернет-пространства (интернет как «всесильный актор» [6, с. 5], ярко выраженная интернет-зависимость, обращение к интернету в любой ситуации и, как подтверждение, появление сопутствующей терминологии, например «загугли», «заскайпись», «залей» и т. д.);

4) отсутствие критического осмысления множественных потоков информации (неумение «отфильтровывать» значимые сообщения, достоверные источники, восприятие только актуализированных в медиапространстве социальных проблем и «повесток дня», что приводит к дезинформированности);

5) ущерб другим видам деятельности и формам социальной активности;

6) модификация русского языка (преднамеренное и непреднамеренное изменение орфографрии, толкования слов, их упрощение, сокращение, трансформация, появление интернет-сленга);

7) приобщение к девиантным видам поведения (сетевые сообщества с элементами девиации, ксенофобии, расизма, национализма, экстремизма и др.).

Деструктивно-социализирующие интенции соцмедиа связаны с тем, что в социальных сетях любая идея более концентрирована, локализирована и быстро находит свое место в определенных группах. К сожалению, с максимальной легкостью в экстремистские группировки рекрутируются молодые люди с активной гражданской позицией, что обосновывается искусной подменой патриотизма, еще чаще умеренного национализма, обозначаемого в современном дискурсе оксюмороном «здоровый» национализм, - идеологическими иллюзиями лжепатриотизма.

По официальной статистике МВД РФ за январь - июнь 2016 г. зарегистрировано 830 преступлений экстремистской направленности, что на 10,72 \% больше, чем в 2015 г., и 1313 преступлений террористического характера, что на 42,73 \% больше зарегистрированных в 2015 г. [7]. Вместе с тем эксперты единогласно отмечают возрастание молодежного киберэкстремизма. Интеграция двух наиболее опасных основных тенденций современного экстремизма - молодежного и информационного - приводит к распространению экстремистских аксиологических установок и формированию благоприятной среды для его развития.

Под информационным, сетевым экстремизмом следует понимать «деятельность, осуществляемую с использованием информационных технологий, сопряженную с формами социально-психического и опосредованного физического деструктивного влияния, результатом которого является достижение публично нелегитимных и противоправных целей» [8, с. 11]. На сегодняшний день феедеральный список экстремистских материалов, опубликованный на сайте Министерства юстиции РФ, включает 4010 единиц, что почти в 2 раза больше, чем в 2013 г. За 2016 г., по подсчетам Freedom House, на 60,0 \% увеличилось количество сайтов с экстремистским содержанием, впоследствии заблокированных. Число киберпреступлений, судя по возбужденным уголовным делам в отношении веб-активистов, возросло с 38 до 130 за последние три года.

Киберэкстремизм можно считать одним из подвидов «информационного экстремизма», который в свою очередь характеризуется следующими параметрами [9, с. 12]:

1) безличность, анонимность;

2) аморальность (фрагментарность функционирования духовно-нравственного пространства, как заключает Е.О. Кубякин, «это открывает простор для интенсивного развития экстремистской деятельности»);

3) радикальность;

4) антисоциальность (создает конфоликтогенное пространство);

5) институциональность (на уровне маргинального пространства);

6) искаженность политико-правового мышления;

7) противоправность результатов.

Подчеркнем, что типичный киберэкстремист - это молодой человек в возрасте от 20 до 25 лет, преимущественно из неблагополучной семьи. Начальник отделения УФСБ РФ по Новосибирской области А. Седых отмечает, что на данный момент треть экстремистских преступлений совершается с помощью социальной сети «ВКонтакте», их количество увеличивается в геометрической прогрессии, очень остро стоит проблема противодействия подобному экстремизму: «Социальные сети, коммуникативное пространство развивается гораздо быстрее, чем аппарат контроля за ними...» [10]. «ВКонтакте» насчитывает более 380 млн пользователей, и неудивительно, что в 
данной сети распространяются экстремистские материалы - все отследить крайне сложно, но каждый год возбуждается все больше уголовных дел. Этот же факт подтверждает глава Управления МВД по региону П. Золотухин, который сообщает, что если в 2010 г. случаи экстремистских интернет-преступлений были единичны, то на сегодняшний день ситуация обратная: «Выкладываются видеоролики, ранее признанные экстремистскими материалы, это могут быть брошюры, высказывания, создаются экстремистские группы» [11]. При этом по оценкам иностранных экспертов из правозащитной организации Freedom House, проанализировавшей онлайн-тренды 60 стран, интернет-пространство РФ является лишь частично свободным по сравнению с показателями предыдущих годов: «В рейтинге свободы Россия заняла 41-е место из 100» [12]. Снижение уровня свободы в интернете связано с новыми законами о фильтрации веб-контента.

Распространение киберэкстремизма в молодежной среде связано с появлением новых, все более изощренных способов вербовки. Усугубляют положение простота и доступность виртуальной формы рекрутирования, в особенности через социальные сети. Благодаря возможности свободно и анонимно контактировать в интернет-пространстве, по словам Д.А. Нечитайло, «за последние 10 лет было подготовлено 120 известных экстремистов». Посредством мониторинга виртуального пространства были выявлены следующие методы вербовки молодежи в социальных сетях (на примере «ВКонтакте»):

1. Метод воронки - вовлечение в «раскрученные» группы с большим количеством реальных и «фейковых» участников, поддерживающих данную идеологию, т. е. акцентируется единство взглядов, что подтверждает наши изыскания относительно роли проблем с идентичностью.

2. Контекстный метод - вовлечение в латентные группы, привлекающие внимание с помощью интересного, социально значимого контекста и преследующие якобы другие - легитимные, благородные - цели, например благотворительность, акции социальной защиты, акции протестного характера - митинги против абортов, курения, наркотиков, а также акции в поддержку чего-либо или мероприятия, посвященные историческим событиям.

3. Метод «закрытого клуба», где экстремистская ячейка представлена как некая элитарная группа, культивирующая принадлежность общине, якобы обладающая уникальными истинными знаниями и наделяющая своих членов фантомной властью для разного рода деятельности, направленной на глобальные социальные изменения.

4. Метод мотивационного рекрутирования, главный принцип которого - спровоцировать инициативность, активность, максимально описать выгоды, возможности самоактуализации, что приводит к трансферу миссии группы в личные цели.

5. Метод «холодных контактов» с использованием всевозможных способов заинтересовать и ненавязчиво привлечь к экстремистской деятельности.

6. Метод «квазипатриотизма» применяют экстремистские организации, обозначающие себя как умеренное, чаще всего патриотическое, течение.

7. Метод «латентный» в основном используется не в чистом виде, а в комплексе с другими и предполагает первичное обращение через объявления, сообщения в «личку» (рассылки) полускрытого характера, не содержащие название, истинные цели группы, например: «ищем тех, кому небезразлична такая-то проблема». Экстремистская организация видится молодым людям как средство самореализации.

Таким образом, молодежный экстремизм в современных условиях характеризуется повышенным уровнем социальной дезадаптации личности, диффузностью идентичности, распространением информационно-коммуникативных технологий и требует рационального сокращения неконтролируемого пространства социализации. Подчеркнем, что чаще всего молодежный экстремизм в РФ - это конфрликт стереотипов и идей. Профиллактика молодежного киберэкстремизма должна основываться на усилении роли традиционных институтов социализации, поддержании новых институтов морали и снижении деструктивного потенциала молодежных объединений.

\section{Ссылки:}

1. Данилова М.А. Интернет в повседневной жизни студенческой молодежи // Инновационное общество: национальная безопасность России в сценариях столкновения цивилизаций : сб. науч. ст. всерос. науч.-практ. конф. Саратов, 2008. C. $176-178$.

2. Кастельс М. Становление общества сетевых структур // Новая постиндустриальная волна на Западе: антология. М., 1999.

3. Иванов Д.В. Виртуализация общества. СПб., 2000. 96 с.

4. Гудков Л., Дубин Б. Институциональные дефициты как проблема постсоветского общества // Мониторинг общественного мнения. 2003. № 3 (65). С. 33-52.

5. Славин Б.Б. «Сетевые революции», или новая социализация общества // Казанская наука. 2011. № 3. С. $204-206$.

6. Данилова М.А. Интернет-социализация студенческой молодежи: специфика мотивации сетевого поведения : автореф. дис. ... канд. социол. наук. Саратов, 2009. 18 с.

7. Состояние преступности в РФ за 2016 г. [Электронный ресурc]. URL: https://mBд.pф/reports (дата обращения: 14.12.2016). 
8. Упорников Р.В. Политико-правовые технологии противодействия информационному экстремизму в России : автореф. дис. ... канд. юрид. наук. Ростов н/Д., 2007. С. 11.

9. Там же. С. 12.

10. Новосибирская полиция и ФСБ заявили о росте экстремизма «ВКонтакте» [Электронный ресурc]. URL: http://www.rocit.ru/articles/novosibirskaya-politsiya-i-fsb-zayavili-o-roste-ekstremizma-vkontakte (дата обращения: 11.12.2016)

11. Полиция и ФСБ заявили о росте экстремизма в интернете [Электронный pecypc]. URL: http://news.ngs.ru/more/1417048/ (дата обращения: 15.12.2016)

12. Ошаров P. Россия с «частично свободным» Интернетом [Электронный ресурc]. URL: http://www.golos-ameriki.ru/content/internet-freedom-in-the-world/1762425.html (дата обращения: 15.12.2016).

\section{References:}

Castells, M 1999, 'The formation of the network society', Novaya postindustrial'naya volna na Zapade: antologiya, Moscow, (in Russian).

Danilova, MA 2008, 'Internet in everyday life of students', Innovatsionnoye obshchestvo: natsional'naya bezopasnost' Rossii $v$ stsenariyakh stolknoveniya tsivilizatsiy : sb. nauch. st. vseros. nauch.-prakt. konf., Saratov, pp. 176-178, (in Russian).

Danilova, MA 2009, Internet socialization of students: the specific features of network behavior motivation, PhD in Social Science thesis abstract, Saratov, 18 p., (in Russian).

Gudkov, L \& Dubin, B 2003, 'Institutional deficit as a problem of post-Soviet society', Monitoring obshchestvennogo mneniya, no. 3 (65), pp. 33-52, (in Russian).

Ivanov, DV 2000, Society virtualization, St.-Petersburg, 96 p., (in Russian).

Osharov, R 2016, Russia with the "partially free" Internet, viewed 15 December 2016, <http://www.golos-ameriki.ru/content/internet-freedom-in-the-world/1762425.html>, (in Russian).

Slavin, BB 2011, '“Network revolutions”, or a new socialization of society', Kazanskaya nauka, no. 3, pp. 204-206, (in Russian). Upornikov, RV 2007, Political and legal technologies to discourage information extremism in Russia, PhD in Law thesis abstract, Rostov-on-Don, p. 11, (in Russian). 